\title{
Spigelian hernia. Personal experience and review of the literature
}

\author{
A. Ruiz de la Hermosa, I. Amunategui Prats, P. Machado Liendo, F. Nevarez Noboa and \\ A. Muñoz Calero \\ Gregorio Marañón University Hospital. Department of General Surgery I. Madrid, Spain
}

\begin{abstract}
Objective: Spigelian hernia is an uncommon abdominal wall defect. We present our series of patients with Spigelian hernia and a literature review.

Patients: We carried out a retrospective review of patients operated on from 2001 to 2008. Epidemiological aspects, diagnostic methods, surgical technique characteristics, morbidity, hospital stay, recurrences and follow up are analyzed.

Results: We have treated 39 patients, 25 female and 14 male, with a mean age of 70 years. Left side was the most frequent location. Risk factors were present in $74 \%$ of patients. Diagnosis was made clinically in $72 \%$ of cases. Open hernioplasty followed by laparoscopic hernioplasty are the most frequent techniques performed. Emergency operation was needed in 20\% of patients. Postoperative morbidity is very low.

Conclusions: Diagnosis of Spigelian hernia is basically clinic. The gold standard is TC in doubtful cases. An important percentage of patients will present with an acute complication of the Spigelian hernia as their first symptom. Surgical technique depends on patient characteristics, type of hernia and surgeon experience.
\end{abstract}

Key words: Spigelian hernia. Ventral hernia. Laparoscopy. Mesh.

\section{RESUMEN}

Objetivo: la hernia de Spiegel es una variedad poco frecuente de defecto de la pared abdominal. Presentamos nuestra serie de pacientes intervenidos con éste diagnóstico, así como una revisión de la literatura.

Pacientes: se realiza un estudio retrospectivo de los pacientes intervenidos por hernia de Spiegel en nuestro centro entre los

Received: 22-02-10

Accepted: $18-03-10$.

Correspondence: Alicia Ruiz de la Hermosa. Servicio de Cirugía General I. Hospital General Universitario Gregorio Marañón. C/ Doctor Esquerdo, 46. 28007 Madrid, Spain.e-mail: aliciaruiz9@hotmail.com años 2001 y 2008. Se analizan factores epidemiológicos, forma de diagnóstico, características de la técnica quirúrgica, morbilidad, estancia hospitalaria, recidivas y seguimiento.

Resultados: han sido intervenidos 39 pacientes, 25 mujeres y 14 hombres, con una edad media de 70 años. La localización más frecuente es la izquierda. El 74\% de los pacientes presenta 1 o más factores de riesgo. El diagnóstico fue clínico en el $72 \%$ de los casos. La técnica más empleada es la hernioplastia seguida de la hernioplastia laparoscópica y en el $20 \%$ de los casos la intervención tuvo que realizarse de forma urgente. La morbilidad postoperatoria es escasa.

Conclusiones: el diagnóstico de la hernia de Spiegel es fundamentalmente clínico. En caso de duda diagnóstica el TAC es la prueba de elección. En un porcentaje importante de pacientes la primera manifestación es la incarceración. La técnica quirúrgica dependerá de las características del paciente, la hernia y la experiencia del cirujano

Palabras clave: Hernia de Spiegel. Hernia ventral lateral. Laparoscopia. Malla.

Ruiz de la Hermosa A, Amunategui Prats I, Machado Liendo $P$, Nevarez Noboa F, Muñoz Calero A. Spigelian hernia. Personal experience and review of the literature. Rev Esp Enferm Dig 2010; 102: 583-586.

\section{INTRODUCTION}

Spigelian hernia is an uncommon variety of abdominal wall defect. It constitutes $0.1-2 \%$ of all abdominal wall hernias. It is also called spontaneous lateral ventral hernia, hernia of semilunar line, hernia of the conjoint tendon or interstitial ventral hernia. Spigelian hernia appears between the fascia of the anterior rectus, internal oblique and transverse abdominal muscles. It occurs because of a 
weak area of spiegelian fascia which is localized between the semilunar line and the lateral edge of the anterior rectus muscle. The semilunar line extends from the costal margin to the pubic spine and it shows transitional area from muscle to aponeurosis of the transverse muscle of the abdomen. Most of these hernias occur distal to the umbilicus, within the spigelian hernia belt or Spangen area which is a transverse band between the line joining both anterior superior iliac spines and a parallel line $6 \mathrm{~cm}$ cranial at the level of the umbilicus $(1,2)$.

Although congenital cases have been described the most of Spigelian hernias are acquired and some risk factors are related to it, such as obesity, COPD, presence of other hernias and abdominal traumas $(2,3)$.

The symptoms can vary and are non specific. The most frequent symptom is pain and the presence of a lump. When the hernia sac contents the bowel the patient can present with nausea, vomiting or altered bowel rhythm. Clinical diagnosis does require a high index of suspicion. The presence of pain and a palpable lump in the typical location should alert us of its diagnosis. However it could be difficult to identify them during the physical examination as the hernia sac is located beneath the aponeurosis of the external oblique. A delay in the diagnosis leads to a high rate of complications and the need of emergency surgery in many cases (3).

We present the results of our own series and a literature review.

\section{PATIENTS AND METHODS}

We carried out a retrospective review of patients operated on from 2001 to 2008 at our Hospital. The assessed parameters were as follows: epidemiological aspects (age, gender), associated risk factors (obesity, COPD, previous abdominal surgery, other associated hernias), symptoms of presentation, diagnostic methods (clinical or radiological), surgical technique characteristics (elective or emergency operation, hernioplasty or herniorraphy, open or laparoscopic approach) morbidity, hospital stay, recurrences and follow-up.

\section{RESULTS}

Between January 2001 and December 2008, 39 patients underwent surgery for Spigelian hernia. Twenty five patients $(64.1 \%)$ were females and 14 patients $(35.9 \%)$ were males. The mean age was 70 years (range 37-92 years). Left side was the most frequent location, 17 patients $(44 \%)$ and three patients $(8 \%)$ had a bilateral Spigelian hernia. Risk factors were present in $74 \%$ of patients and a history of previous abdominal operation was the most frequent one. In $41 \%$ the Spigelian hernia appeared concomitantly with other type of abdominal wall hernia. The most frequent symptom was pain and it was reported in 24 of our 39 patients $(61 \%)$. In 12 of 39 (31\%) an abdominal lump was present and only $3(8 \%)$ had bowel obstruction symptoms. Out of 11 patients with radiological preoperative examinations, diagnosis was made clinically based on anamnesis and physical examination in 28 cases (72\%). Emergency surgery was performed in 8 patients (20\%) due to a complication.

Open hernioplasty with polypropylene mesh placed underneath the external oblique aponeurosis constitutes the most frequent technique (67\%), followed by laparoscopic hernioplasty placing a bilaminar mesh in intraperitoneal position $(23 \%)$. The remaining $10 \%$ of cases were repair with a herniorraphy. In two patients a bowel resection was needed because of incarceration although the hernia sac content found was usually preperitoneal fat or omentum. The $23 \%$ of patients required surgical repair of another abdominal wall hernia during the operation for Spigelian hernia (2 umbilical hernioplasties, 2 umbilical herniorraphies, 5 inguinal hernioplasties).

During the postoperative care one patient had a wound infection and another one had a paralytic ileus. There was neither serious morbidity nor mortality. Mean hospital stay was 2.6 days, however if we look the cases that required an emergency operation this number rise to 4 days.

Two recurrences $(5 \%)$ were noted during the followup, which have already been operated on and one patient presented with a contralateral Spigelian hernia.

\section{DISCUSIÓN}

The Spigelian hernia $(\mathrm{SH})$ takes its name from the French anatomist Adriaan van Spieghel, who described the semilunar line for the first time in 1645 . However it was Klinkosch in 1764 who first described a spontaneous lateral ventral hernia at the level of Spieghel's semilunar line (4). To date Spanish reports on this pathology are short series of cases, being the largest one published by Moreno-Egea et al in 2002 with 27 patients (5). Subsequently Moles Morenilla et al made a bibliographic review of Spanish literature in 2003 that included 167 patients (1). After this report only isolated cases, congenital SH associated with cryptorchidism or the SatorrasFioretti review about abdominal wall hernias of unusual presentation which included 12 patients with Spigelian hernia (6) have been published. The hernia appears to peak in the fifth decade of life and is more common in women. There are no significant differences in literature about their right or left location and there aren't in our series either. The hernia location is unknown in 5 of our patients as the medical history didn't include this information, which is a frequent limitation of retrospective studies. Bilateral Spigelian hernias are very unusual (7) and only a few instances have been reported, however 3 of our patients (8\%) had a bilateral SH and during the follow-up a fourth patient was diagnosed of a Spigelian her- 
nia in the opposite side to the Spigelian hernia previously operated on. Frequently these hernias are associated to other abdominal wall hernias either treated previously or coexisting in up to $50 \%$, that is why is very important to rule out that possibility (6). We found associated hernias in 16 patients (41\%), although only 9 were repaired at the same surgical act.

In addition to previous or concomitant hernias as a risk factor we have also looked for other medical conditions such as COPD or prior abdominal surgery. We found 29 patients $(74 \%)$ with at least one of those risks factors. Other predisposing factors are obesity and abdominal traumas but they cannot be considered in our study because the lost of information exceeded $20 \%$ as it was not available in the medical charts. The presence of any of these situations must be regarded as a starting point for correctly orienting clinical history and should lead to the diagnosis. Other authors published variable data ranged between the $62 \%$ found by Cerdán Pascual (2) to the $100 \%$ reported by Ríos (8); other authors have similar data to ours such as the 79\% published by Artioukh (9).

Most of SH are situated underneath the external oblique muscle, between the different sheaths of abdominal wall, and therefore, SH are also called interstitial, intraparietal or occult hernias. That special location of $\mathrm{SH}$ contributes to hinder the diagnosis. Only a small percentage of SH (0.8\%) are superficial (1). In these cases the hernia sac penetrates the external oblique aponeurosis and lie below the subcutaneous fat making easy during physical examination to feel the bulge. A very important factor to be aware of during physical examination is the difference between lower SH and inguinal hernias. Lower SH are below the level of the inferior epigastric vessels and that can lead to mistake a $\mathrm{SH}$ for an inguinal hernia. Some authors report up to $50 \%$ of cases with an incorrect diagnosis (10).

Symptoms can vary and mostly are unspecific so that a delayed diagnosis is frequent. Pain is in our series the most frequent symptom, usually referred to the hernia site, however the presence of pain in literature ranges from $31 \%$ to $86 \%(9,11)$. Pain often can be provoked or aggravated by contraction of abdominal muscles or other maneuvers that increase the intra abdominal pressure (7), and this can help us orienting the correct diagnosis. The second symptom in frequency in our patients is the presence of a lump, but as mentioned above, due to anatomical characteristics of $\mathrm{SH}$, the lump may be not palpable as shown by Moles et al who refer the $12.5 \%$ of cases with no lump (12). Other common symptoms are nausea, vomiting and altered bowel rhythm although all these vary depending on hernia sac content. Some cases are asymptomatic (3\%) and are discovered during a routine medical checkup or intraoperatively during a surgical operation for other medical problem (1). All of our patients had symptomatic $\mathrm{SH}$.

Although diagnosis must be established clinically in most patients on the basis of a high level of suspicion, a proper anamnesis and a thorough physical examination, it is not possible in some cases. In those cases of diagnostic doubt is advisable to perform a sonography or tomography $(13,14)$. These techniques can help to make a diagnosis and specially can provide data on the exact location of the defect, size, environment and hernia sac content. The use of imaging techniques ranged from $30 \%$ to $100 \%$ in different series $(15,16)$. Ultrasonography can establish the diagnosis but provides less specificity than CT scan as has quite false negatives in obesity patients. CT scan is the recommended investigational imaging study, moreover if laparoscopic approach is going to be employed so that any hernia sac content can be properly identified $(17,6)$. Diagnosis was preoperative in all patients our series $(72 \%$ clinically and $28 \%$ after imaging studies). Literature series obtained preoperative diagnosis between 47 and $92 \%$ $(1,2,11,18)$. In contrast to programmed surgery, the emergency surgery performed at our hospital required radiological confirmation in up to $88 \%$ (6 CT scanning, 1 ultrasonography and 1 clinically).

Despite all this help that imaging techniques offer there is still a small percentage of patients requiring emergency surgery: $21 \%$ for Moreno-Egea (5), the same as Artioukh (9) and very similar to the $20 \%$ in our series, $33 \%$ for Popovici (19) and over than $40 \%$ for Moles Morenilla (1).

The treatment of Spigelian hernia is surgical and can be performed either by classic open or laparoscopic technique. Open approach follows the usual principles of any hernia repair. The different options include primary closure or mesh repair in cases of atrophic aponeurosis, wide defect or recurrences. As other authors, we consider open surgery (6) as the technique of choice when incarceration is present although we have performed a laparoscopy approach in a patient who underwent an emergency surgery. That case presented as an incarcerated Spigelian hernia but during ultrasonography exploration it got reduce. Laparoscopy approach allowed us to explore abdominal cavity and rule out any damage to the bowel loops that could have passed unnoticed.

In 1992, Carter y Mizes performed the first intra-abdominal laparoscopic correction (20) and in 1995, Salvador et al published the first one in Spain (21). After that laparoscopic approach has been widely described in literature. Two treatment modalities can be used, transperitoneal so called intra-abdominal and extraperitoneal. The first one allows to explore the contralateral side as well as the abdominal cavity and for some authors is the recommended method when there is another process requiring associated surgery because can be performed in the same intervention (6). We do not completely agree with this opinion as we think a prosthetic material should not be implanted at the same time that any other surgical procedure with risk of contamination. The second modality of endoscopic treatment is the extraperitoneal approach that offers the advantage 
of avoiding general anesthesia so that can be performed easily as an outpatient procedure and also avoids the possible added risk of visceral lesions as demonstrates the only prospective randomized controlled trial comparing conventional versus laparoscopic management of Spigelian hernia (22).

Generally speaking, laparoscopic approach results in less infection rate, quicker incorporation to activities of daily living, less postoperative pain and specially avoids opening the external oblique aponeurosis and therefore a risk reduction of recurrence (1). In our experience laparoscopic approach has been employed successfully in 9 patients $(23 \%)$. We have used intra-abdominal modality in all cases and we do not have experience with totally extraperitoneal technique, although is the recommended by most authors.

Apart from the type of surgical approach exists discussion about the need of a prosthetic mesh. Some authors obtain without mesh as good results as with it, and they currently recommend mesh-free repair, either for conventional repair like Hsieh (23) or for laparoscopy repair like Bittner (24). Anyway the number of patients of these studies is very small to find statistical differences. Published results with any of the existing techniques are good as regards the low recurrence rate that ranges from 0 to $8 \%(1,6,25,26)$. We had $2(5 \%)$ recurrences (1 elective and 1 emergency surgery) and in both of them the initial surgery was a primary closure and in the reoperation a mesh was used. As regards to postoperative morbidity literature describes minimal and mild complications such as wound infections, paralytic ileus or haematomas. Analysis of morbidity in our patients shown 2 complications (5\%), which is similar to the $0-16 \%$ published by other authors $(5,6,25)$.

To conclude we stress that diagnosis and treatment of Spigelian hernias is still a controversial matter, basically for the varied and uncommon presentation. Sometimes the way of presentation is a complication that requires emergency surgery. Spigelian hernias have a multidisciplinary interest and their diagnosis involves various specialities such us surgeons, radiologists and in some instances internists and gastroenterologists when the SP presents as abdominal pain syndromes. A high index of suspicion and a thorough physical examination is needed to make a correct diagnosis, although in doubtful cases it is advisable to perform a sonography or better a tomography. The treatment of Spigelian hernia should be surgical. Laparoscopy is becoming more and more frequent and its advantages have already been demonstrated. In spite of this, laparoscopy in not always available for emergency surgery and also requires a learning curve. Modality of laparoscopic treatment is still on discussion. In our experience intraabdominal approach is easy to perform and gives good results.

\section{REFERENCES}

1. Moles Morenilla L, Docobo Durántez F, Mena Robles J, Quinta Frutos R. Spigelian hernia in Spain. An analysis of 162 cases.. Rev Esp Enferm Dig 2005; 97(5): 338-47.

2. Cerdán Pascual R, Cantín Blázquez S, Barranco Domínguez JI, Bernal Jaulín J, Duque Mallén MV. Hernia de Spiegel. Revisión a propósito de 8 casos. Rev Cubana Cir 2005; 44(4).

3. Zaragoza C, Villalba S, Castaño S, Trullenque R. Hernia de Spiegel. Cir Esp 1996; 59: 165-7.

4. Klinkosch JT. Programma Quo Divisionem Herniarum, Novumque Herniae Ventralis Specium Proponit. Rotterdam: Benam; 1764.

5. Moreno-Egea A, Flores B, Girela E, Martín JG, Aguayo JL, Canteras M. Spigelian hernia: bibliographical study and presentation of a series of 28 patients. Hernia 2002; 6: 167-70.

6. Satorras-Fioretti M, Vázquez-Cancelo J, Pigni-Benzo L, Salem AM, Ramos-Ardá A. Hernias de pared abdominal de localización poco frecuente. Cir Esp 2006; 79(3): 180-3.

7. Weis Y, Lernau O, Nissan S. Spigelian Hernia. Ann Surg 1974; 180 (6): 836-9.

8. Ríos A, Rodríguez JM, González R, Ortiz S, Carrasco M, Parrilla P. Hernia de Spiegel: múltiples presentaciones de una hernia poco frecuente. Cir Esp 1999; 65: 123-6.

9. Artioukh DY, Walker SJ. Spigelian herniae: presentation, diagnosis and treatment. J R Coll Surg Edinb 1996; 41: 241-3.

10. Stirnemann H. The Spigelian hernia: missed? Rare? Puzzling diagnosis? Chirurg 1982; 53: 314-7.

11. Fernández L, Roig J, Monzón A, Gómez A, Pellicer J, Tieso A, et al. Hernia de Spiegel: a propósito de siete casos. Rev Esp Enf Ap Digest 1989; 75: 267-70

12. Moles Morenilla L, Fernández J, Ortiz C, Quinta R, Díaz E, Ramos J Hernia de Spiegel. A propósito de 16 casos. Cir Esp 2000; 67: 572-5.

13. Mufid MM, Abu-Yousef MM, Kakish ME, Urdaneta LF, Al-Jurf AS Spigelian hernia: diagnosis by high-resolution real-time sonography. J Ultrasound Med 1997; 16: 183-7.

14. Shenouda NF, Hyames BB, Rosenblum MB. Evaluation of spigelian hernia by CT. J Comput Assist Tomogr 1990; 12: 777-8.

15. Vos D, Scheltinga M. Incidence and outcome of surgical repair of spigelian hernia. Br J Surg 2004; 91: 640-4.

16. Malazgirt Z, Dervisoglu A, Polat C, et al. Preperitoneal mesh repair of spigelian hernias under local anestesia: description and clinical evaluation of a new technique. Hernia 2003; 7 : 202-5.

17. Moreno-Egea A, Flores B, Aguayo J, et al. La hernia de Spiegel en España: revisión bibliográfica y presentación de una serie personal de 27 pacientes. Cir Esp 2002; 72: 18-22.

18. Coda A, Mattio R, Bona A, Filippa C, Ramellini G, Ferri F. Spigelian hernia: an up-to-date. Minerva Chir 2000; 55: 437-41.

19. Popovici A, Munteanu I. Spigelian hernias. The authors' own experience and a review of the literature. Chirurgia 1997; 92: 179-86

20. Carter JE, Mizes C. Laparoscopic diagnosis and repair of spigelian hernia: report of a case and technique. Am J Obstet Gynecol 1992; 167: 77-8.16.

21. Salvador JL, Laguna M, Adell R, García R, Gibert J. Reparación de la hernia de Spiegel por vía laparoscópica. Rev Esp Enferm Dig 1995; 87: 759-60.

22. Moreno-Egea A, Carrasco L, Girela E, et al. Open vs. Laparoscopic repair of spigelian hernia: a prospective randomized trial. Arch Surg 2002; 137: 1266-8.

23. Hsieh HF, Chuang CH, Lin $\mathrm{Ch}, \mathrm{Yu}$ JC, Hsieh CB. Spiegelian hernia: mesh or not? Rev Esp Enferm Dig 2007; 99(9): 502-4.

24. Bittner JG 4th, Edwards MA, Shah MB, MacFadyen BV Jr, Mellinger JD. Mesh-free laparoscopic spigelian hernia repair. Am Surg 2008; 74(8): 713-20; discussion 720 .

25. Mittal T, Kumar V, Khullar R, Sharma A, Soni V, Baijal M, Chowbey PK. Diagnosis and management of Spigelian hernia: A review of literature and our experience. J Minim Access Surg 2008; 4(4): 95-8.

26. Louring-Andersen M, Hjorne FP, Skovdal J, Bisgaard T. Diagnosis and treatment of Spigelian hernia. Ugeskr Laeger 2009; 171(48): 3518-22. 